\title{
Retrospective Comparative Study of Clinical Outcome of X ray Based Versus Computed Tomography Based Treatment Planning in Conventional Radiotherapy in Carcinoma Cervix
}

\author{
Authors \\ Minakshi Roy, Vinita Trivedi, Rita Rani, Richa Chauhan, Usha Singh
}

\begin{abstract}
Introduction: In conventional radiotherapy of carcinoma cervix treatment planning can be done by $X$ ray simulation or CT simulation.

Objectives: To analyze whether CT simulation can provide better treatment outcome in carcinoma cervix.

Methods: 182 patients of carcinoma cervix treated in our institute in the time period 2010-2011 and matched the inclusion criteria of study (age between 50 to 65 years, stage IIA to IIIB, has taken minimum 3 cycle of concurrent chemotherapy) was analysed for their clinical outcome in terms of treatment failure, distant metastasis, loco regional recurrence, residual disease.

Results: CT based planning showed better treatment outcome in terms of less distance mets, residual disease, loco regional recurrence and improved disease-free survival and overall survival.

Conclusion: CT based radiotherapy planning has improved clinical outcome in case of carcinoma cervix. So CT based radiotherapy planning is a good option for carcinoma cervix patient who do not afford $3 D$ CRT.
\end{abstract}

\section{Introduction}

In the state of Bihar in India, most of the cervical cancer patients are from low socioeconomic status and are of advanced stage. In advanced stages of disease proper nodal coverage is needed to prevent treatment failure. Most of these patients of $\mathrm{Ca}$ cervix are not affording for 3DCRT (3 Dimensional Conformal Radio Therapy) or IMRT (Intensity modulated Radio Therapy) and are being treated in our hospital by conventional $\mathrm{X}$ ray based radiotherapy. For curative treatment for locally advanced carcinoma cervix the gross disease and the tissue at potential risk of disease spread along with pelvic nodes should be irradiated properly. Conventional $\mathrm{X}$ ray based radiotherapy treatment planning is based on bony landmarks. So soft tissue cannot be assessed in this radiotherapy technique. To overcome this limitation conformal radiotherapy technique based on CT (Computer Tomography) scan or MRI (Magnetic Resonance Imaging) is used. By this technique proper target delineation can be done and normal tissue can be spared from irradiation accordingly. Hence more precise treatment can be given. In developed countries 3DCRT and IMRT is increasingly used now a days. ${ }^{[1]}$

\section{Objectives}

To analyze whether CT based planning in conventional radiotherapy can provide better 
treatment outcome in carcinoma cervix than $\mathrm{X}$ ray based planning.

\section{Methods}

All cases of carcinoma cervix treated in our institute in the year 2010-2011 were retrospectively analysed and the patients who satisfied the eligibility criteria were included in our study.

Inclusion criteria of study were age between 50 to 65 years, stage IIA to IIIB, has taken minimum 3 cycle of concurrent chemotherapy and treated by conventional radiotherapy.

Exclusion criteria of study were age less than 50 years and more than 65 years, stage IA,IB, IVA, IVB and has taken less than 3 cycle of concurrent chemotherapy. In our hospital conventional radiotherapy is done by $\mathrm{X}$ ray based planning or CT based planning.

Total 182 patients satisfied the inclusion criteria. 55 patients had CT based planning and 127 patients had X ray based planning. Median follow up was 2 years. Patients were analysed for their clinical outcome in terms of distant metastasis, loco regional recurrence, residual disease, disease free survival and overall survival.

\section{Results}

55 patients had CT based planning and 127 patients had X ray based planning. After median follow up of 2 years treatment failure was seen in $9.09 \%$ in case of CT based planning and $25.19 \%$ in case of $\mathrm{X}$ ray based planning. Distant metastasis, loco regional recurrence, residual disease seen in $1.8 \%, 5.45 \%, 1.8 \%$ case of CT based planning and in $14.96 \%, 7.87 \%, 2.36 \%$ case of $X$ ray based planning respectively.

The median overall survival and disease free survival for CT planning is 23 and 18 months respectively whereas the same for $\mathrm{X}$ ray based planning is 18 and 14 months respectively.

\begin{tabular}{|l|c|c|c|}
\hline & CT SCAN & X-RAY & P VALUE \\
\hline LOCO REGIONAL RECURRENCE & $3(5.45 \%)$ & $10(7.87 \%)$ & 0.001 (significant) \\
\hline RESIDUAL & $1(1.82 \%)$ & $3(2.36 \%)$ & 0.07 \\
\hline DISTANT METS & $1(1.82 \%)$ & $19(14.96 \%)$ & 0.008 (significant) \\
\hline
\end{tabular}

\begin{tabular}{|l|c|c|c|}
\hline & CT SCAN & X-RAY & P VALUE \\
\hline $\begin{array}{l}\text { DFS (MEAN } \pm \text { SEM) } \\
(\text { MONTHS) }\end{array}$ & $16.58 \pm 1.342$ & $15.19 \pm 1.008$ & 0.2731 \\
\hline OS (MEAN \pm SEM) (MONTHS) & $20.02 \pm 1.312$ & $18.97 \pm 1.004$ & 0.2109 \\
\hline $\begin{array}{l}\text { Total treatment time (MEAN } \pm \text { SEM) } \\
\text { (WEEKS) }\end{array}$ & $9.600 \pm 0.5148$ & $9.299 \pm 0.3000$ & 0.2714 \\
\hline
\end{tabular}




\section{JMSCR Vol||07||Issue||03||Page 1382-1387||March}

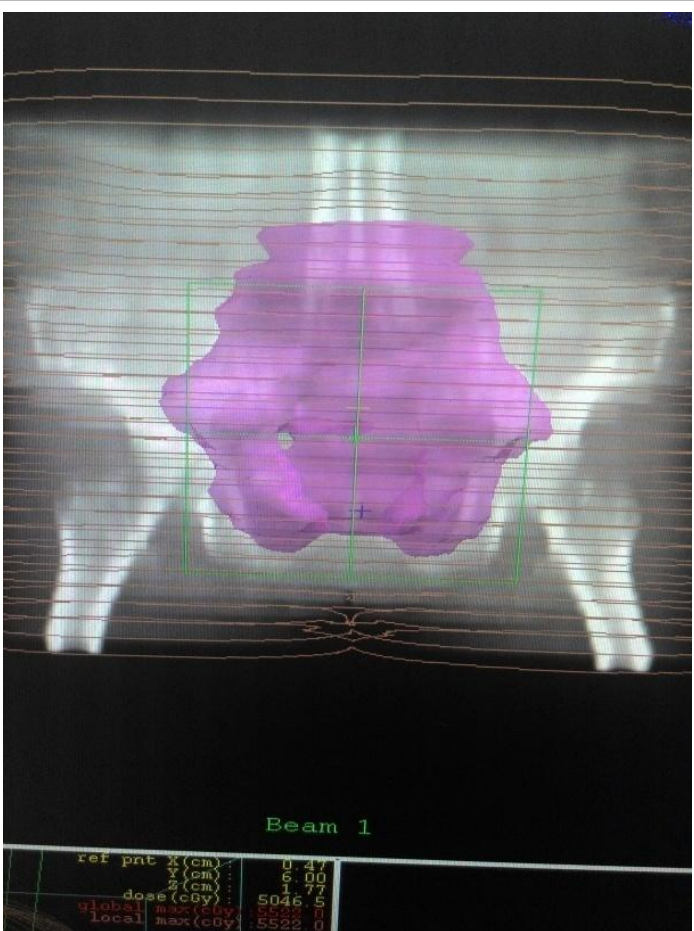

Fig 1: Dose Coverage Area in CT Based Planning

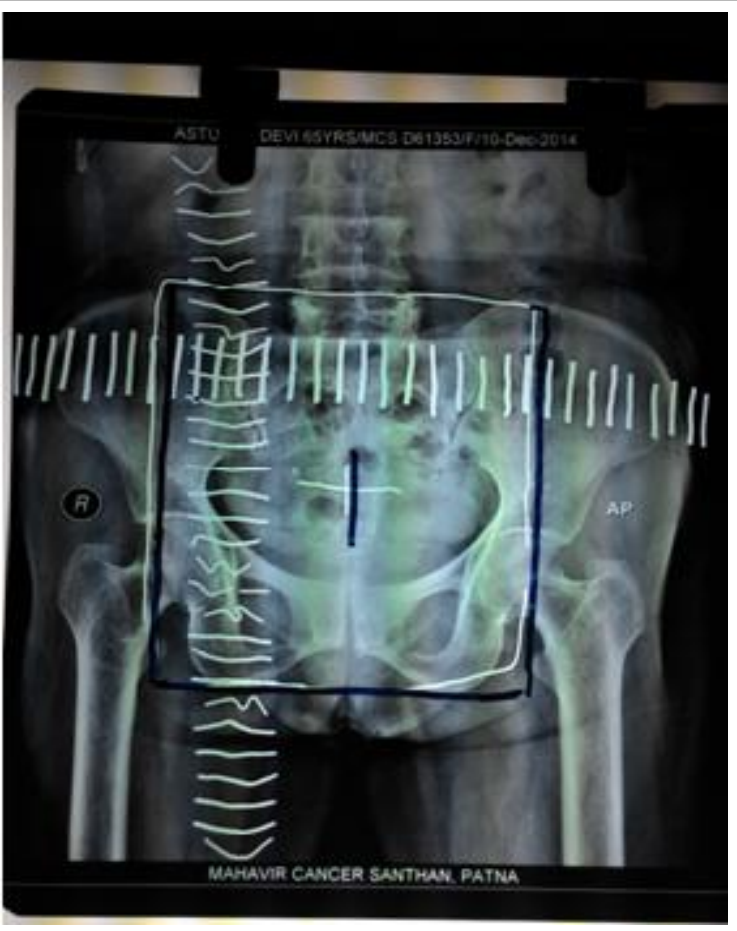

Fig 2: Portal for X ray Based Planning

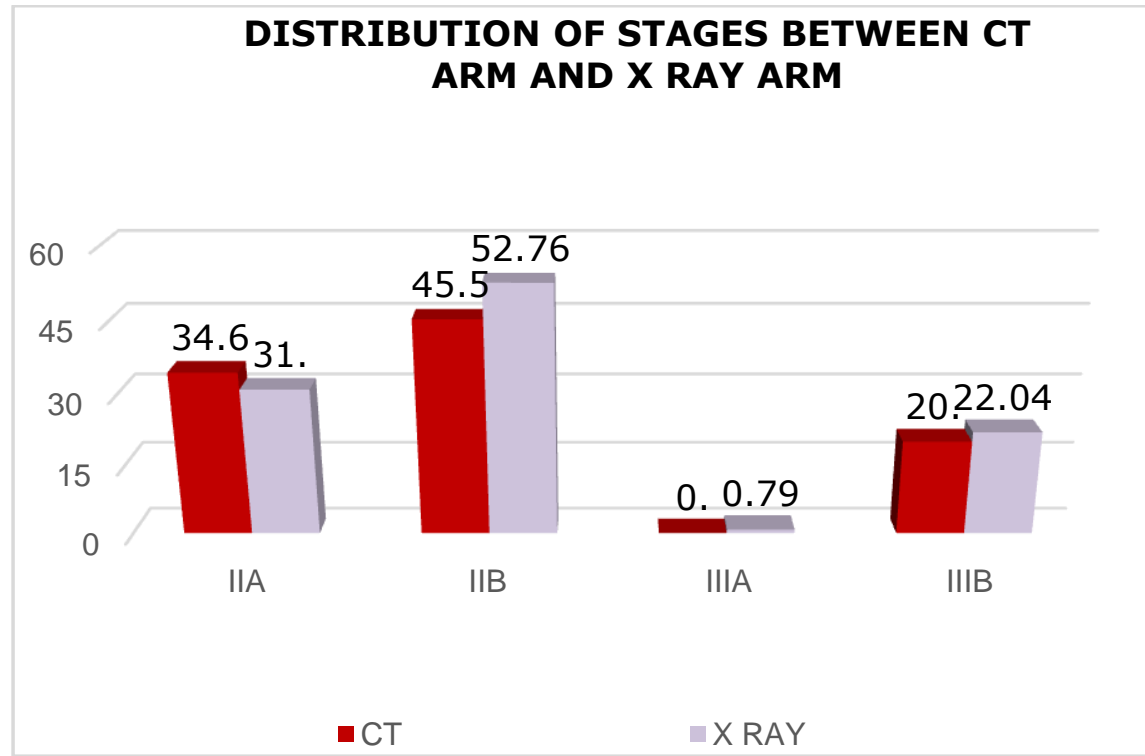

Fig 3: Distribution of Stages between CT Arm and X Ray Arm

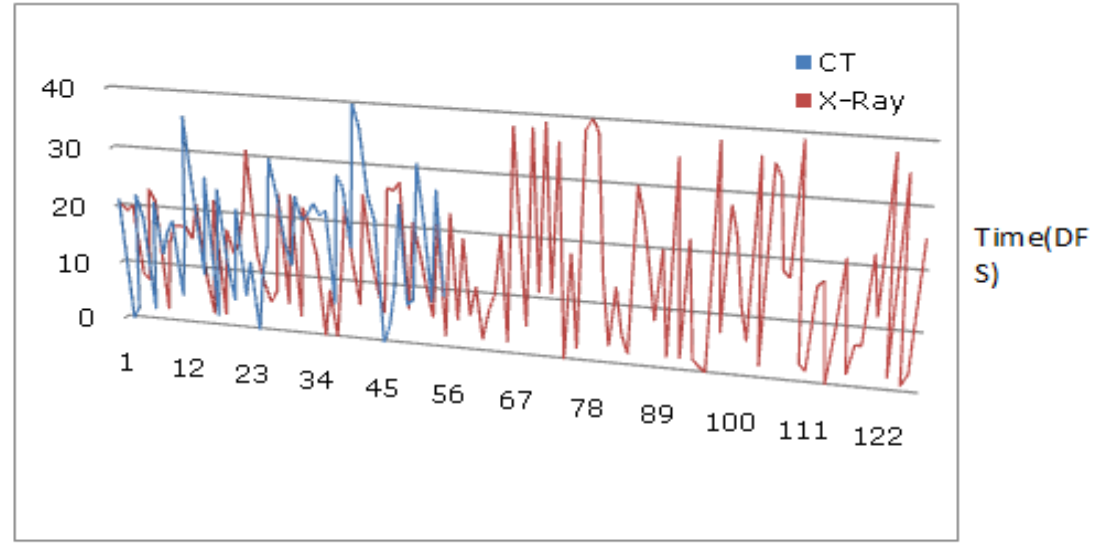

Number of Patients

Fig 4: DFS in patients of CT ARM and XRAY ARM 


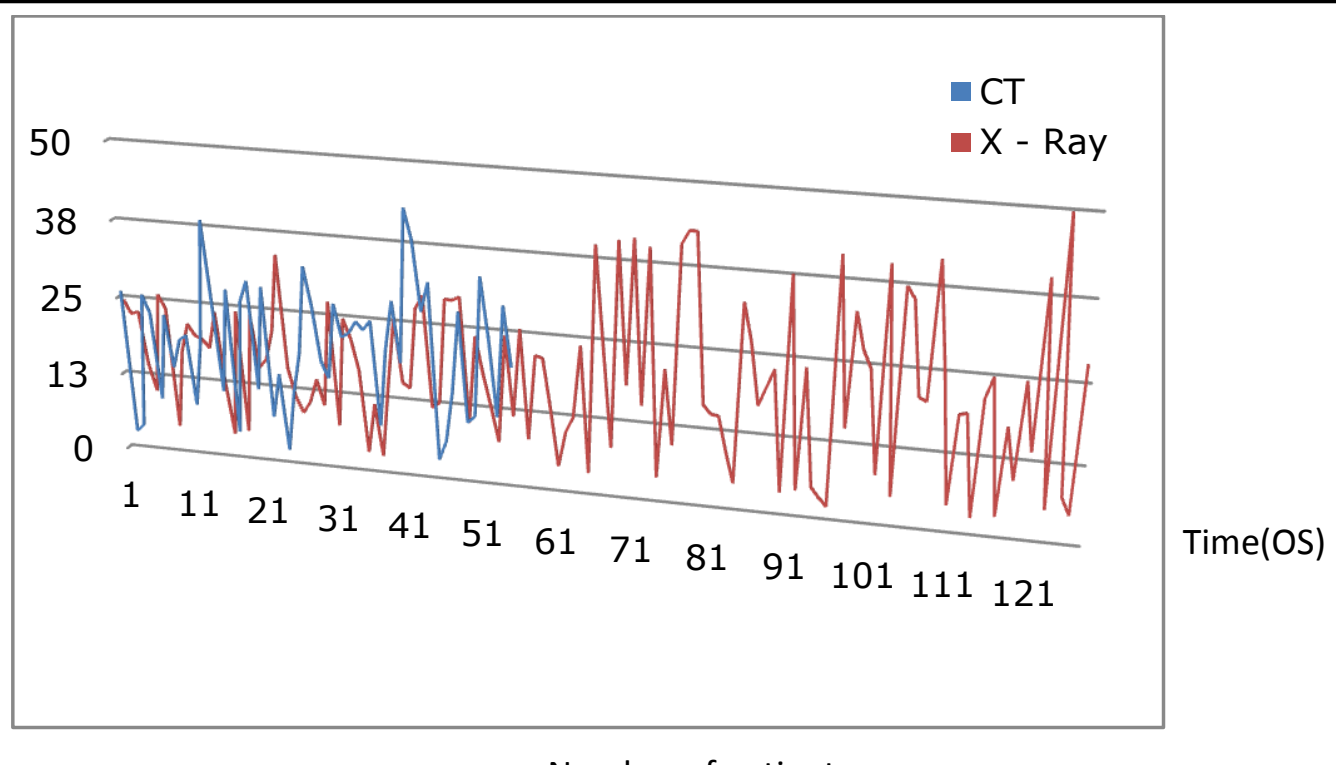

Number of patients

Fig 5: Overall Survival in Patients of CT ARM and XRAY ARM

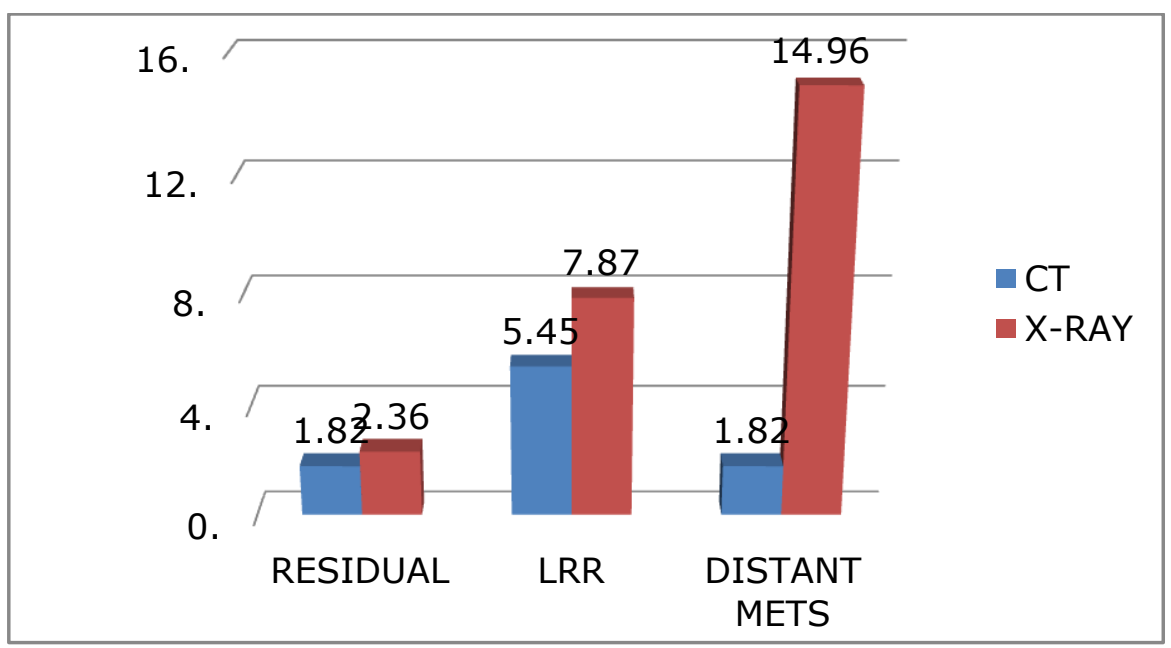

Fig 6: Treatment Failure in CT ARM and XRAY ARM

\section{Discussion}

In early stage of cervical carcinoma radiotherapy and surgery has comparable results. ${ }^{[2]}$ For locally advanced stage standard treatment is concomitant chemo-radiotherapy. 5 yr. survival rate in stage III disease is $30-50 \%$ and that of stage IV disease is $10-20 \%{ }^{[3,4]}$ Concurrent chemotherapy, when used along with radiotherapy increases the progression free survival and overall survival compared to radiotherapy alone. For curative treatment of locally advanced carcinoma cervix the gross disease and the tissue at potential risk of disease spread along with pelvic nodes should be irradiated properly. Radiotherapy can be delivered either in two dimensional conventional technique or three dimensional conformal technique. In developed countries 3DCRT is being used increasingly as the standard of care in ca cervix. ${ }^{[5]}$ This technique provides good loco regional control and acceptable toxicity profile. ${ }^{[6-8]}$ To decrease the normal tissue toxicity conformal radiotherapy technique was invented. But in developing countries due to high patient load, lack of facilities and un affordability of poor patient 2D conventional radiotherapy planning is much more used. Conventional radiotherapy can be planed by either bony landmark based or CT based planning. The superior border of four field box technique of bony landmark based conventional planning is kept at L4-L5 junction. 
Inferior border at lower border of obturator foramen or $2 \mathrm{~cm}$ below the lower extent of disease. Lateral border at $2 \mathrm{~cm}$ lateral to lateral pelvic brim. Anterior border is kept in front of pubic symphysis. Posterior border is at S2-S3 junction. In CT based planning we can include common iliac nodes and external iliac nodes by tracing the aortic bifurcation and external iliac artery respectively. So less chance of geographic miss of potential area of tumor harbour which ultimately improves treatment outcome. In our study we have found CT based planning improved the clinical outcome in ca cervix. In 1990 an intraoperative study by Greer et al. ${ }^{[9]} 100$ patients was performed in which pelvic structures were measured and the measurement was correlated with lymphatic drainage. It was found that aortic bifurcation was located at an average $6.7 \mathrm{~cm}$ above lumbosacral prominence and it was concluded that conventional radiotherapy field is unable to include pelvic lymph node properly. In 1992 Russel et al. ${ }^{[10]}$ studied sagittal MRI in design of lateral treatment portal in locally advanced carcinoma cervix. Conventional lateral portal could not cover uterine fundus in $62.5 \%$ cases. And it was concluded by author that lateral treatment portals designs should be based on imaging in the treatment position, not depending on an assumption of normal anatomic relationship. In 1999, a study was conducted by Zunino et al. ${ }^{[11]}$ to review the radiation therapy of cervical carcinoma by box technique with the help of MRI, lymphangiography and anatomic study on cadavers. This study was performed in 35 patients of carcinoma cervix. It was observed that posterior and anterior border was inadequate in $49 \%$ and $9 \%$ cases respectively. In a study by McAlpine et al. ${ }^{[12]}$ it was discovered that $26 \%$ of patients would have inadequate lateral coverage on the AP/PA portals and there was a significant miss $(39 \%)$ of common iliac lymph nodes. In an MRI based study by Justino et al. 16 it was observed that portals of four field box technique was inadequate in $56 \%$ of cases. In a dosimetric study by Abhishek Gulia et al. ${ }^{[1]} 4 \%$ of study population had adequate target volume coverage by standard $\mathrm{X}$ ray based planning and inadequacy of target volume coverage was seen in $96 \%$ patients for superior border and in 54\% patients for lateral border. In a cadaveric study by Khamanarong $\mathrm{K}$ et al. $^{[13]}$ it was found aortic bifurcation at the level of L4 vertebra in $70.1 \%$ of cases, at the fourth lumbar intervertebral disc in $12.3 \%$ of cases, and at the level of L5 vertebra in $17.6 \%$ of cases. A study was conducted by Chithriki $\mathrm{M}$ et al. ${ }^{[14]}$ to determine the aortic bifurcation level with the help of MRI. Aortic bifurcation was noted in front of L4 vertebra in two third of cases.

\section{Conclusion}

CT based planning can give better target coverage than $\mathrm{X}$ ray based planning which ultimately improves treatment outcome. So in poor socio economic strata where three dimensional conformal radiotherapy outweigh the affordability of patients, we can offer better treatment by CT based planning in conventional radiotherapy.

\section{References}

1. Gulia A, Patel F, Rai B, Bansal A, Sharma S C. "Conventional four field radiotherapy versus computed tomography-based treatment planning in cancer cervix: A dosimetric study." South Asian journal of cancer 2013;2:132. [PubMed]

2. Landoni F, Maneo A, Colombo A, Placa F, Milani R, Perego P et al. Randomised study of radical surgery versus radiotherapy for stage Ib-IIa cervical cancer. Lancet. 1997;350:535-40 [PubMed]

3. Horiot JC, Pigneux J, Pourquier $\mathrm{H}$, Schraub S, Achille E, Keiling $\mathrm{R}$ et al. Radiotherapy alone in carcinoma of the intact uterine cervix according to G. H. Fletcher guidelines: A French cooperative study of 2383 cases. Int J Radiat Oncol Biol Phys 1988;14:605-611. [PubMed]

4. Perez CA, Grigsby PW, Nene SM, Camel H M, Galakatos A, Kao M S et al. Effect 
of tumor size on the prognosis of carcinoma of the uterine cervix treated with irradiation alone. Cancer 1992;69:2796-2806 [Google Scholar]

5. Goswami J, Patra NB, Sarkar B, Basu A, Pal S. Dosimetric comparison between conventional and conformal radiotherapy for carcinoma cervix: Are we treating the right volumes? South Asian J Cancer. 2013;2:128-31. [PubMed]

6. Saibishkumar EP, Patel FD, Sharma SC. Results of radiotherapy alone in the treatment of carcinoma of uterine cervix: A retrospective analysis of 1069 patients. Int J Gynaecol Cancer. 2005;15:890-7. [PubMed]

7. Saibishkumar EP, Patel FD, Sharma SC. Evaluation of late toxicities of patients with carcinoma of cervix treated with radical radiotherapy: An audit from India. Clin Oncol. 2006;18:30-7. [PubMed]

8. Lanciano RM, Pajak TF, Martz K, Hanks GE. The influence of treatment time on outcome for squamous cell cancer of the uterine cervix treated with radiation: A patterns-of-care study. Int J Radiat Oncol Biol Phys. 1993;25:391-7. [PubMed]

9. Greer BE, Koh WJ, Figge DC, Russell AH, Cain JM, Tamimi HK. Gynaecologic radiotherapy fields defined by intraoperative measurements. Gynecol Oncol. 1990;38:421-4. [PubMed]

10. Russell AH, Walter J, Anderson MW, Zukowski CL. Sagittal magnetic resonance imaging in the design of lateral radiation treatment portals for patients with locally advanced squamous cancer of the cervix. Int J Radiat Oncol Biol Phys 1992;23:449455. [PubMed]

11. Zunino S, Rosato O, Lucino S, Jauregui E, Rossi L, Venencia D. Anatomic study of the pelvis in carcinoma of uterine cervix as related to the box technique. Int $\mathrm{J}$ Radiat Oncol Biol Phys. 1999;44:53-9. [PubMed]
12. Mc Alpine A, Schlaereth JB, Lim P, Chen D, Eisenkop SM, Spiritos NM. Radiation fields in gynecologic oncology: Correlation of soft tissue (surgical) to radiologic landmarks. Gynecol Oncol. 2004; 92:25-30.[PubMed]

13. Khamanarong K, Sae-Jung S, Supa-Adirek C, Teerakul S, Prachaney P. Aortic bifurcation: a cadaveric study of its relationship to the spine. $\mathrm{J}$ Med Assoc Thai 2009 Jan;92:47-9. [PubMed]

14. Chithriki M, Jaibaji M, Steele RD. The anatomical relationship of the aortic bifurcation to the lumbar vertebrae: a MRI study. Surg RadiolAnat2002;24:308-12. [PubMed]. 